\title{
Khat chewing among Ethiopian University Students- a growing concern
}

Ewenat Gebrehanna ${ }^{1 *}$, Yemane Berhane ${ }^{1}$ and Alemayehu Worku ${ }^{1,2}$

\begin{abstract}
Background: Khat has amphetamine like effect. Students chew khat to stay alert. It has various negative physical, mental, social and cognitive effects. Poor academic performance has been associated with khat. The purpose of this study was to determine the prevalence and identify factors associated with khat chewing among Ethiopian University students.

Methods: A cross sectional study was conducted on Bahir Dar University Students. A self-administered questionnaire was completed by 3268 students. Proportion was calculated to estimate prevalence of khat chewing. Logistic regression was used to identify factors associated with khat chewing.

Results: Lifetime prevalence of khat chewing was 24\% (95\% Confidence Interval: 22.5\%, 26.6\%). Half of these are current khat users with a prevalence of 12.7\% (95\% Confidence Interval: 11.5\%, 13.9\%). Male students Adjusted Odds Ratio $(A O R)=3.3$ (95\% Confidence Interval: 1.8, 6.0), students living in off campus housing AOR = 3.0 (95\% Confidence Interval: 1.5, 6.0), students who have khat user friends $A O R=4.2$ (95\% Confidence Interval: $2.6,6.9)$, and students who perceive khat use improves academic performance AOR $=6.6$ (95\% Confidence Interval: $4.6,9.5)$ are more likely to use khat.
\end{abstract}

Conclusions: Prevalence of current use of khat reported in this study is higher than recent study done on university students in Ethiopia and heavily influenced with peer practice.

Keywords: Khat chewing, Ethiopia, University students

\section{Background}

Khat is a plant with amphetamine like characteristics with effects including insomnia, euphoria, decreased fatigue and suppressed appetite when chewed [1]. Frequent and chronic khat use has been associated with various consequences. These include substance dependency [2], early sexual debut [3] unprotected sex [4] mental health issues $[5,6]$ and with various social, cognitive and financial problems [7-10].

Ethiopia is one of several countries in Africa and the Middle East where khat chewing is common. A national study reported $23.0 \%$ of out-of-school and $7.5 \%$ of inschool adolescents use khat [4]. A separate study estimated prevalence of khat use in the general population of Ethiopia was $27.3 \%$ among men and $11.0 \%$ among women of 15-49 years in 2011 [11].

\footnotetext{
* Correspondence: gewenat@gmail.com

${ }^{1}$ Addis Continental Institute of Public Health, Addis Ababa, Ethiopia

Full list of author information is available at the end of the article
}

Khat is consumed by students when they wish to study for long hours especially during examination periods [12]. In Ethiopia there have been few studies of khat use among university students. The available studies were either done before the expansion of public universities and increased admission loads or represent only a single faculty/department of a university which might affect estimation of khat use among university students. The study conducted in 2002 among Gondar School of Medical Science and Bahir Dar polytechnic - and Pedagogy Colleges reveled a prevalence of $17.5 \%$ [13]. This study was conducted before universities expanded to the current level as explained later on. Other, more recent studies, reported prevalence of $14.4 \%$ from a study done on technology and pharmacy faculties of Addis Ababa University [14]; 2.3\% among Medical faculty students of Addis Ababa University [15]; 6.3\% from Debremarkos polytechnic college [16]; 27.9\% from Axum University 
[17]; and $12.9 \%$ from private and public colleges in Bahir Dar city [18].

Socio-demographic characteristics such as being male, having pee $r$ influence and student seniority have been associated with khat chewing [19-21]. The most common reasons $g$ ven for chewing khat include: staying alert and achieving better concentration at work; increasing motivation when there is a need to work long hours; socializing; and other recreational purposes [13,22].

Ethiopia has markedly expanded the number and admission capacity of public universities in the last decades. The numbers of public universities under the Federal Ministry of Education (MoE) have increased from less than ten in 2004/2005 academic year to thirty-one in 2013/2014. Currently four additional universities are in line to join these universities [23]. This expansion has also changed the diversity of students. Different regions and cultural groups are better represented. Undergraduate students are assigned to public universities from all over the country by the Ministry of Education of Ethiopia (MoE). Due to this process students at public universities in Ethiopia are composed of different ethnic and cultural backgrounds.

Knowing the prevalence and reasons for khat chewing among university students is important because of its serious health, social and economic consequences. Khat use among university students in Ethiopia has been studied as early as 1988 [24]. However recently the diversity of university students have changed following expansion of higher education in Ethiopia. In addition most recent studies on khat use among Ethiopian university students were done on single faculties or departments, which may not represent the whole university student community. Those factors outside of the university campus, such as living arrangements, that may affect students' khat use are not well documented. Therefore, this study was designed to assess the prevalence and reasons for khat chewing among university students in the current context of university setups using representative sample size from Bahir Dar University.

\section{Methods}

\section{Study area}

A cross sectional study was conducted among University students of Bahir Dar University, Ethiopia, in June 2012. During the 2011/2012 academic year, Bahir Dar University enrolled 15,066 regular undergraduate students. Of which 32,66 (21.7\%) were female [25]. Bahir Dar University has academic units which include 3 faculties, 4 Colleges, 3 Institutes, and two academies.

\section{Sample size and sampling}

Sample size for the study was determined by using a single population formula to determine prevalence and a two population formula to identify factors across year of study. The assumption for sample size calculation was that khat chewing will be affected by the length of stay at university (Year of study). We have calculated sample size for each year of study using Epiinfo version 3.5.1. The maximum sample size was taken for the data collection. With the exception of one academy which didn't have a regular undergraduate education, all academic units within the university were included. All regular undergraduate students were eligible for the study. The sample size calculated was distributed for each academic unit based on the number of students. Sampling was further refined by taking into consideration the male to female student ratio. Then, students were selected using a simple random sampling procedure from the registrar office lists.

\section{Study tool}

Data were collected using a structured pre-tested, self-administered questionnaire. The questionnaire was developed based on literature and previously-used questionnaires. In addition, a formative qualitative assessment was done in Gondar University, a public university located $180 \mathrm{Km}$ north from Bahir Dar University. Gondar University, also a public university, has student admission, accommodation, and academic systems similar to Bahir Dar University. The surrounding communities both around Gondar and Bahir Dar Universities share similar language and culture. The formative assessment identified current issues around khat use among university students. Some of the issues that arose during the formative assessment include students' khat chewing habit off campus and how khat chewer students cluster together. Following the formative assessment, a questionnaire was developed, and a pretest was conducted at Gondar University. The questionnaire was prepared and administered in English and Amharic (Ethiopian official language) so that participants could choose either language.

\section{Data collection}

Only students selected for the study were asked to remain in their classroom to complete a self-administered questionnaire. Students were given detailed explanation of the study and how to fill the questionnaire by trained facilitators. As khat use has some level of stigma, a social desirability bias was expected. To minimize this potential bias, students were given the maximum privacy by not allowing instructors or any other member of the Bahir Dar University staff not to enter in the classrooms during data collection and by arranging the seats with enough space between students.

\section{Measuring prevalence}

Khat use was measured as ever and current use. Ever use was defined as khat use experience at any time 
during their lifetime. Current use was defined as use of khat during the current academic year and classified into three categories: current academic year (September 2011June 2012); during the current second semester (Feb-June 2012); and during the last four weeks preceding the survey (which was June 2012).

\section{Habitual use}

Current users were classified into habitual and occasional users. Habitual use was defined as khat chewing at least once a week while occasional use was defined as khat chewing less than once in a week.

\section{Statistical analysis}

Prevalence was calculated with $95 \%$ confidence interval (CI) to describe ever and current khat use as defined above. Bivariate and multivariable logistic regressions were done to assess association between khat chewing and selected factors. Socio-demographic and economic variables, friends' characteristics, perceptions about khat, living arrangements, and family history of khat use were considered in the bivariate logistic regression. Only variables associated with khat chewing at p-value 0.2 or less during the bivariate logistic regression were entered into the multivariable logistic regression model. Variables with very low cell values (less than 5) were excluded from logistic regression to maintain the stability of the models.

\section{Ethical issues}

The study protocol was approved by the Ethical Review Board of Bahir Dar University. Informed consent was obtained from each participant and participation into the study was fully voluntary. Study participant students were offered refreshment worth 5 Ethiopian Birr (0.28 USD) at the university student café to compensate the time spent on responding to the survey.

\section{Results}

A total of 3,872 students were invited to participate in the study and of which 3,268 completed and returned the self-administered questionnaire. Of those, 3,001 questionnaires were completely filled and included for analysis in this paper. Thus, the overall response rate was $77.5 \%$. The majority of respondent were male (77.6\%), Orthodox Christians (81.8\%), living on campus (96.1\%) (Table 1).

The overall prevalence of lifetime khat use is $24.0 \%$ (95\% CI: 22.5\%, 25.6\%). Current use of khat is reported by $12.7 \%$ (95\% CI: $11.5 \%-13.9 \%)$ of students. The prevalence of habitual khat use is reported by $4.8 \%$ (95\% CI: $4.0 \%, 5.6 \%)$. Khat chewing occurs more frequently among male students than females in all categories (Figure 1).

An Adjusted Odds Ratio (AOR) was calculated to various factors that are likely to be associated with ever, current (chewing in the current academic year) and
Table 1 Profile of study participant Bahir Dar University Students, Ethiopia 2012

\begin{tabular}{|c|c|c|}
\hline & Frequency & Percentage \\
\hline \multicolumn{3}{|l|}{$\overline{S e x}$} \\
\hline Male & 2328 & 77.6 \\
\hline Female & 673 & 22.4 \\
\hline \multicolumn{3}{|l|}{ Year of study } \\
\hline Year 1 & 834 & 27.8 \\
\hline Year 2 & 823 & 27.4 \\
\hline Year 3 & 824 & 27.5 \\
\hline Year 4 and above & 520 & 17.3 \\
\hline \multicolumn{3}{|l|}{ Average monthly pocket money } \\
\hline Doesn't receive pocket money & 251 & 8.0 \\
\hline Less than 100 Birr & 533 & 16.9 \\
\hline 100-199 & 646 & 20.5 \\
\hline 200-299 & 587 & 18.7 \\
\hline 300-399 & 414 & 13.2 \\
\hline $400-499$ & 238 & 7.6 \\
\hline 500 or above & 476 & 15.1 \\
\hline \multicolumn{3}{|l|}{ Religion } \\
\hline Orthodox & 2437 & 81.8 \\
\hline Catholic & 19 & 0.6 \\
\hline Protestant & 262 & 8.8 \\
\hline Muslim & 227 & 7.6 \\
\hline No religion & 14 & 0.5 \\
\hline Others & 21 & 0.7 \\
\hline \multicolumn{3}{|l|}{ On campus housing } \\
\hline Yes & 2771 & 96.1 \\
\hline No & 114 & 3.9 \\
\hline
\end{tabular}

habitual khat use (Table 2). Male students were more likely to chew khat in the current academic year as compared to female students $[\mathrm{AOR}=3.3(95 \% \mathrm{CI}: 1.8,6.0)]$. Students who perceive that khat helps to study better were more than 6 times more likely to chew khat in the current academic year as compared to those who do not $[\mathrm{AOR}=6.6$ (95\% CI: 4.6, 9.5)]. Students who live in off campus housing were 3 times more likely to chew khat in the current academic year as compared to those students who reside on campus $[\mathrm{AOR}=3.0$ (95\% CI: 1.5 , 6.0)]. Students were more likely to chew khat if they have close friends who are khat chewers compared to those who do not have friends who chew khat at all $[\mathrm{AOR}=4.2(95 \% \mathrm{CI}: 2.6,6.9)]$. IStudents that reported family history of khat chewing were more likely to chew khat than students who reported no family history of khat use $[\mathrm{AOR}=2.8(1.9,4.2)]$. These factors were found to be cross-cutting factors across the three categories of khat use (Table 2). 


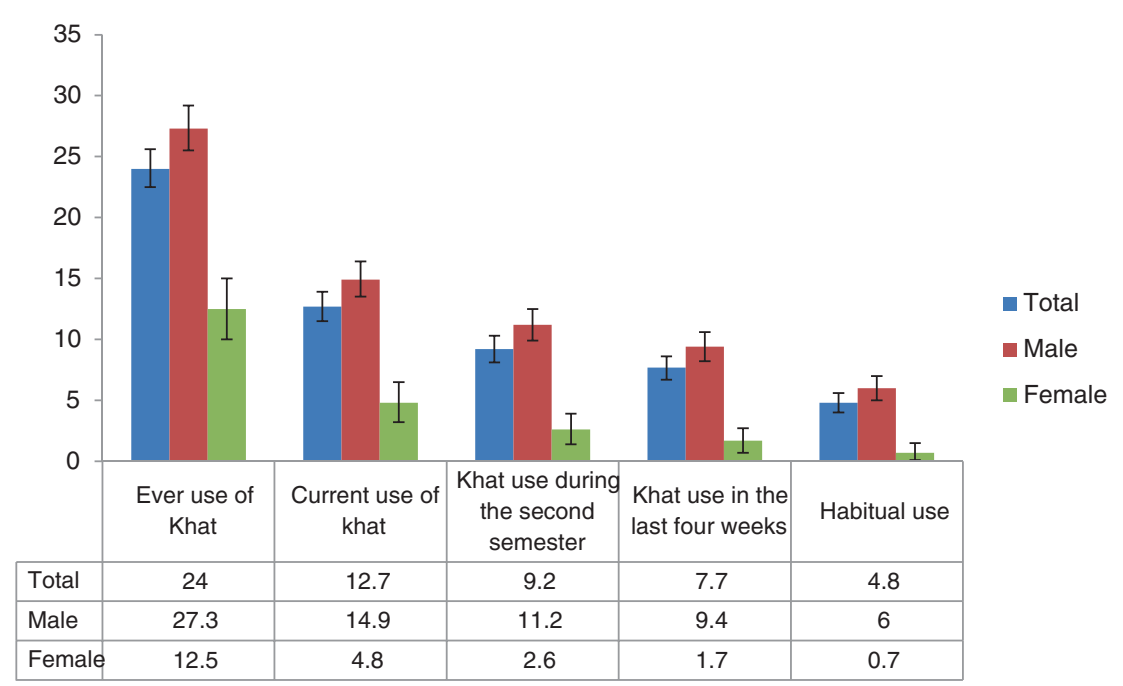

Figure 1 Prevalence of khat chewing across different reference time by sex among Bahir Dar University Students, June 2012.

\section{Discussion}

About a fourth of university students, $24.0 \%$, have ever chewed khat, and about 1 in 8 reported chewing khat during the academic year in which the study was conducted. Male students were more likely to chew khat. Students living in off campus housing, those having a chewer friend, and those having a positive perception of khat benefits for studying well were also more likely to use khat.

This study provides a more accurate prevalence of khat use as compared to most of the recent studies on khat use among university students in Ethiopia. This study has much larger sample size which represent all the undergraduate students compared to previous studies conducted among University students in Ethiopia [13,15]. In addition, male and female students were selected for the study proportionally considering the actual male to female student ratio at Bahir Dar University during the study period thus avoiding representation bias.

Majority of the non-response rate in this study was accounted for by the absence of the students in the graduating class who left the campus for internships off campus during the study period. The absence of the students is likely to underestimate the prevalence of khat use. Due to this non-response, we might not have detected the actual difference of khat use across study years. Previous study on university students of Ethiopia has shown an increase combined prevalence of khat use and cigarette smoking [13]. Studies elsewhere have shown increased prevalence of substance use among college students as year of study increases [26].

The current study has reported a $24.0 \%$ lifetime use of khat which is similar to previously reported lifetime prevalence in 2002 [13]. However, recent use of khat measured during the four-week data collection period was different from $17.5 \%$ in 2002 [13] to $7.7 \%$ in this study. Another study done among Addis Ababa University Medical students reported four week khat use prevalence of 3.7\%, which is lower than the 2002 report [15] as well as the current study. Current reports of lower khat use among university students may not be a real decline but due to change in social and demographic diversity of students that followed the wide expansion of higher education in Ethiopia after 2002 [27]. Another explanation is the various definitions used to define current use may have caused the difference. Some of the studies done on khat use among university students didn't establish clear definitions of current khat use $[14,15,18]$.

In this study, prevalence of khat chewingwas higher among male students when measured across different time periods. This is consistent with several studies conducted among higher learning institutions in Ethiopia and elsewhere $[13,15,20,21,28]$. Substance use is mediated by gender identities. Patriarchal societies accept substance use among men more easily than substance use among women allowing men to use substances more than women [29,30]. Men have also more opportunities for substance use putting them at higher risk [26].

This study showed that students who have close friends who chew khat are more likely to use khat. Previous evidences have similar association with khat chewing and friends' khat use $[13,15]$. Khat chewing usually starts during adolescence period and is introduced by friends and peers [31,32]. Other substance use studies have documented that the closeness of friendship as well as the level of friends' influence are strong indicators of substance use among young people $[33,34]$.

Family history of khat use is associated with current khat use by students in this study. This is consistent with previous studies which reported association between 
Table 2 Factors associated with ever, current and habitual use of khat among Bahir Dar University students, Ethiopia 2012

\begin{tabular}{|c|c|c|c|c|c|c|}
\hline & \multicolumn{2}{|c|}{ Ever use of khat } & \multicolumn{2}{|c|}{ Khat use (current academic year) } & \multicolumn{2}{|c|}{ Habitual use of khat } \\
\hline & COR $(95 \% \mathrm{Cl})$ & AOR $(95 \% \mathrm{Cl})$ & COR $(95 \% \mathrm{Cl})$ & AOR $(95 \% \mathrm{Cl})$ & COR $(95 \% \mathrm{Cl})$ & AOR $(95 \% \mathrm{Cl})$ \\
\hline \multicolumn{7}{|l|}{ Sex } \\
\hline Female & 1.0 & 1.0 & 1.0 & 1.0 & 1.0 & 1.0 \\
\hline Male & $2.6(2.0,3.4)$ & $3.1(2.0,4.8)^{* * *}$ & $3.5(2.4,5.1)$ & $3.3(1.8,6.0)^{*}$ & $8.1(3.3,20.0)$ & $4.5(1.4,14.4)^{*}$ \\
\hline \multicolumn{7}{|l|}{ Year of Study } \\
\hline Year 1 & 1.0 & 1.0 & 1.0 & 1.0 & 1.0 & 1.0 \\
\hline Year 2 & $1.4(1.1,1.8)$ & $1.5(1.1,2.2)^{* * *}$ & $1.3(0.9,1.7)$ & $0.9(0.6,1.6)$ & $1.5(0.8,2.7)$ & $0.8(0.3,1.8)$ \\
\hline Year 3 & $1.2(0.9,1.5)$ & $1.7(1.1,2.5)^{*}$ & $1.1(0.8,1.5)$ & $1.3(0.8,2.2)$ & $1.4(0.8,2.4)$ & $1.2(0.5,2.8)$ \\
\hline Year 4 and above & $2.0(1.6,2.6)$ & $1.3(0.8,1.9)$ & $2.4(1.7,3.2)$ & $1.1(0.7,1.8)$ & $4.5(2.7,7.4)$ & $2.0(1.0,4.2)$ \\
\hline \multicolumn{7}{|l|}{ Religion } \\
\hline Orthodox Christian & 1.0 & 1.0 & 1.0 & 1.0 & 1.0 & 1.0 \\
\hline Catholic & $2.7(1.0-7.0)$ & $0.9(0.2,3.9)$ & $3.6(1.3,10.3)$ & $0.9(0.2,5.5)$ & $3.3(0.7,14.6)$ & $0.26(0.01,4.35)$ \\
\hline Protestant & $1.1(0.8,1.5)$ & $1.0(0.6,1.6)$ & $1.1(0.7,1.7)$ & $0.9(0.5,1.6)$ & $1.0(0.5,2.0)$ & $1.0(0.4,2.6)$ \\
\hline Muslim & $4.3(3.3,5.7)$ & $1.7(1.1,2.7)^{*}$ & $4.0(3.0,5.5)$ & $2.1(1.2,3.5)^{* *}$ & $3.4(2.2,5.4)$ & $1.5(0.7,3.0)$ \\
\hline No religion & $6.1(2.0,18.7)$ & $0.8(0.1,5.9)$ & $13.9(4.5,42.8)$ & $2.3(0.3,16.2)$ & $7.4(2.0,27.3)$ & $1.0(0.2,5.3)$ \\
\hline Other & $1.9(0.8,4.7)$ & $1.3(0.3,5.1)$ & $3.5(1.3,9.0)$ & $2.5(0.6,10.7)$ & $4.3(1.3,15.1)$ & $1.7(0.3,11.3)$ \\
\hline \multicolumn{7}{|c|}{ Childhood residence } \\
\hline Rural & 1.0 & 1.0 & 1.0 & 1.0 & 1.0 & 1.0 \\
\hline Small towns & $2.7(2.2,3.4)$ & $1.8(1.3,2.6)^{* *}$ & $3.3(2.4,4.4)$ & $1.6(1.0,2.6)$ & $5.7(3.2,10.3)$ & $1.4(1.0,5.5)$ \\
\hline Big cities & $3.3(2.6,4.2)$ & $2.5(1.7,3.8)^{* * *}$ & $4.7(3.4,6.4)$ & $2.2(1.3,3.7)^{* *}$ & $7.7(4.3,13.9)$ & $1.2(0.5,3.2)$ \\
\hline \multicolumn{7}{|c|}{ Average monthly pocket money received from families and friends } \\
\hline Do not get money & 1.0 & 1.0 & 1.0 & 1.0 & 1.0 & 1.0 \\
\hline$<100$ Birr & $0.4(0.3,0.7)$ & $0.9(0.5,1.7)$ & $0.4(0.2,0.8)$ & $1.0(0.4,2.5)$ & $0.3(0.1,0.8)$ & $0.9(0.2,3.7)$ \\
\hline 100-199 Birr & $0.8(0.5,1.1)$ & $1.1(0.6,2.0)$ & $0.7(0.4,1.2)$ & $1.0(0.4,2.0)$ & $0.4(0.1,0.9)$ & $0.3(0.1,1.1)$ \\
\hline 200-299 Birr & $1.1(0.8,1.6)$ & $1.4(0.8,2.5)$ & $1.2(0.7,2.0)$ & $1.3(0.6,2.8)$ & $1.0(0.4,2.2)$ & $0.9(0.3,2.6)$ \\
\hline 300-399 Birr & $1.5(1.0,2.1)$ & $1.5(0.8,2.7)$ & $2.1(1.2,3.4)$ & $2.1(1.0,4.3)$ & $1.3(0.6,3.0)$ & $0.9(0.3,2.6)$ \\
\hline 400-499 Birr & $1.4(0.9,2.2)$ & $1.0(0.5,2.0)$ & $2.5(1.5,4.3)$ & $2.2(1.0,4.9)$ & $3.3(1.5,7.2)$ & $2.9(1.0,8.5)$ \\
\hline 500 and above & $1.7(1.2,2.4)$ & $1.2(0.6,2.2)$ & $2.8(1.7,4.6)$ & $1.8(0.9,3.8)$ & $2.7(1.3,5.7)$ & $0.8(0.3,2.3)$ \\
\hline \multicolumn{7}{|c|}{ Off Campus Housing } \\
\hline No & 1.0 & 1.0 & 1.0 & 1.0 & 1.0 & 1.0 \\
\hline Yes & $5.0(3.4,7.4)$ & $2.1(1.1,4.1)^{*}$ & $7.4(5.0,11.0)$ & $3.0(1.5,6.0)^{* *}$ & $12.4(7.9,19.7)$ & $6.3(2.9,13.8)^{* * *}$ \\
\hline \multicolumn{7}{|c|}{ Family History of Khat chewing } \\
\hline No & 1.0 & 1.0 & 1.0 & 1.0 & 1.0 & 1.0 \\
\hline Yes & $6.9(5.6,8.5)$ & $3.9(2.8,5.5)^{* * *}$ & $6.8(5.3,8.6)$ & $2.8(1.9,4.2)^{* * *}$ & $6.6(4.6,9.3)$ & $2.4(1.3,4.1)^{* *}$ \\
\hline \multicolumn{7}{|c|}{ Close friends chew Khat } \\
\hline No & 1.0 & 1.0 & 1.0 & 1.0 & 1.0 & 1.0 \\
\hline Yes & $6.6(5.3,8.3)$ & $2.6(1.9,3.7)^{* * *}$ & $13.4(9.3,19.3)$ & $4.2(2.6,6.9)^{* * *}$ & 18.6(9.0, 38.1) & $3.6(1.4,9.3)^{* *}$ \\
\hline \multicolumn{7}{|c|}{ Dorm mates chew khat } \\
\hline No & 1.0 & 1.0 & 1.0 & 1.0 & 1.0 & 1.0 \\
\hline Yes & $3.6(2.9,4.3)$ & $1.4(1.1,2.0)^{*}$ & $5.5(4.3,7.2)$ & $1.9(1.3,2.9)^{* *}$ & $7.8(5.0,12.4)$ & $1.8(0.9,3.4)$ \\
\hline \multicolumn{7}{|c|}{ Believe that Khat helps to study better } \\
\hline No & 1.0 & 1.0 & 1.0 & 1.0 & 1.0 & 1.0 \\
\hline Yes & $9.7(7.7,12.3)$ & $7.5(5.3,10.4)^{* * *}$ & $12.6(9.7,16.3)$ & $6.6(4.6,9.5)^{* * *}$ & $20.2(13.3,30.6)$ & $8.8(5.0,15.4)^{* * *}$ \\
\hline
\end{tabular}


family history and khat use [13,15,35]. This could be due to acceptance of khat use as normative behavior by students whose family members use khat.

Students who reside in off campus accommodation are more likely to be current and habitual chewers. This could be as a result of students' choice of living with other students who have similar interests together exposing them to peer influence [33]. Off campus accommodation is a choice made by individual students. Students with particular characteristics and behavior may choose to live together. This arrangement could be a proximal indicator of students' higher risk of khat and other substance use [36].

Expectation of khat to help students study was the strongest predictor for khat use in this study. The main reason given for chewing khat by students is to concentrate and study well $[13,15]$. This is similar to other substance use studies among university students where expectation of substance to enhance academic performance have been associated with use [37-39]. Studies that examine the association between khat use cognitive response and learning had reported an opposing finding to the positive expectation [10]. Khat has been linked with diminished cognitive capacity and poor academic performance. Khat chewing university students in Ethiopia were found to have a lower mean Cumulative Grade Point Average (CGPA) as compared to non-chewer students [40]. Poorer academic performance was also documented in students in Saudi Arabia [41]. While there has been no evidence that khat affects already stored knowledge, there is evidence that shows its interference in active learning while using it [10]. A study on methamphetamine, use has shown similar relationship between learning and use, where learning is affected once an individual starts using the substance [42]. Khat has similar effects with amphetamine $[43,44]$, which is in turn has weaker, but similar, effect to methamphetamine [45].

\section{Conclusion}

This study has shown that khat use is closely associated with students' contextual environment and expectation of khat. The finding that students have positive expectation of khat for their academic performance conflicts with existing evidences of negative effects of khat on academic performance. This study has also identified that khat use among university students is highly influenced by peer and family khat use.

\section{Competing interests}

The authors declare that they have no competing interests.

\section{Authors' contributions}

EG is the primary investigator responsible for the overall research project. YB and AW were involved in the design, implementation, and analysis and manuscript preparation. All authors read and approved the final manuscript.

\section{Author details}

'Addis Continental Institute of Public Health, Addis Ababa, Ethiopia. ${ }^{2}$ Addis

Ababa University, School of Public Health, Addis Ababa, Ethiopia.

Received: 17 July 2013 Accepted: 6 November 2014

Published: 21 November 2014

\section{References}

1. Dhaifalah I, Santavy J: Khat habit and its health effect. A natural amphetamine. Biomed Pap Med Fac Univ Palacky Olomouc Czech Repub 2004, 148(1):11-15.

2. Kassim $\mathrm{S}$, Croucher R, al'Absi M: Khat dependence syndrome: a cross sectional preliminary evaluation amongst UK-resident Yemeni khat chewers. J Ethnopharmacol 2013, 146(3):835-841.

3. Malaju MT, Asale GA: Association of Khat and alcohol use with HIV infection and age at first sexual initiation among youths visiting HIV testing and counseling centers in Gamo-Gofa Zone, South West Ethiopia. BMC Int Health Hum Rights 2013, 13:10.

4. Kebede D, Alem A, Mitike G, Enquselassie F, Berhane F, Abebe Y, Ayele R, Lemma W, Assefa T, Gebremichael T: Khat and alcohol use and risky sex behaviour among in-school and out-of-school youth in Ethiopia. BMC Public Health 2005, 5:109.

5. Damena T, Mossie A, Tesfaye M: Khat chewing and mental distress: a community based study, in jimma city, southwestern ethiopia. Ethiopian $J$ Health Sci 2011, 21(1):37-45.

6. Bongard S, al'Absi M, Khalii NS, Al Habori M: Khat use and trait anger: effects on affect regulation during an acute stressful challenge. Eur Addict Res 2011, 17(6):285-291.

7. Cox G, Rampes H: Adverse effects of khat: a review. Adv Psychiatr Treat 2003, 9(6):456-463.

8. Halboub E, Dhaifullah E, Abdulhuq M: Khat chewing and smoking effect on oral mucosa: a clinical study. Acta Med (Hradec Kralove) 2009, 52(4):155-158

9. Belew M, Kebede D, Kassaye M, Enquoselassie F: The magnitude of khat use and its association with health, nutrition and socio-economic status. Ethiop Med J 2000, 38(1):11-26.

10. Colzato LS, Ruiz MJ, van den Wildenberg WP, Hommel B: Khat use is associated with impaired working memory and cognitive flexibility. PLOS ONE 2011, 6(6):e20602.

11. Central Statstical Agency of Ethiopia, ICF international: Ethiopia Demographic and Health Survey 2011. 2012th edition. Addis Ababa, Ethiopia: Central Statstical Agency; 2012.

12. Reda AA, Moges A, Biadgilign S, Wondmagegn BY: Prevalence and determinants of khat (Catha edulis) chewing among high school students in eastern Ethiopia: a cross-sectional study. PLOS ONE 2012, 7(3):e33946.

13. Kebede Y: Cigarette smoking and Khat chewing among college students in North West Ethiopia. Ethiop J Health Dev 2002, 16(1):9-17.

14. Eshetu E, Gedif T: Prevalence of khat, cigarette and alcohol Use among students of technology and pharmacy. Addis Ababa University. Ethiop Pharm J 2006, 24(2):116-124.

15. Deressa W, Azazh A: Substance use and its predictors among undergraduate medical students of Addis Ababa University in Ethiopia. BMC Public Health 2011, 11(1):660.

16. Aklog GT, Girmay Tsegay T: Assessment of substance abuse and associated factors among students of Debre Markos Poly Technique College In Debre Markos Town, East Gojjam Zone, Amhara Regional State, Ethiopia, 2013. Global J M Res 2013, 13(4)

17. Gebreslassie M, Feleke A, Melese T: Psychoactive substances use and associated factors among Axum university students, Axum Town, North Ethiopia. BMC Public Health 2013, 13(1):693.

18. Mulugeta $Y$ : Khat chewing and its associated factor among College students in Bahir Dar town. Ethiop Sci J Public Health 2013, 1(5):209-214.

19. Laswar AK, Darwish H: Prevalence of cigarette smoking and khat chewing among Aden university medical students and their relationship to BP and body mass index. Saudi J Kidney Dis Transpl 2009, 20(5):862-866.

20. Wedegaertner F, al-Warith $H$, Hillemacher $T$, te Wildt B, Schneider U, Bleich $\mathrm{S}$, Breitmeier D: Motives for khat use and abstinence in Yemen-a gender perspective. BMC Public Health 2010, 10:735.

21. Nakajima M, al'Absi M, Dokam A, Alsoofi M, Khalil NS, Al Habori M: Gender differences in patterns and correlates of Khat and tobacco use. Nicotine Tob Res 2013, 15(6):1130-1135. 
22. Basunaid S, Dongen MV, Cleophas TJ: Khat abuse in Yemen: a populationbased survey. Clin Res Regul Aff 2008, 25(2):87-92.

23. List of Public Universities in Ethiopia. [http:/www.moe.gov.et/English/ Information/Pages/pubuni.aspx]

24. Zein ZA: Polydrug abuse among Ethiopian university students with particular reference to khat (Catha edulis). J Trop Med Hyg 1988, 91(2):71-75.

25. Ministry of Education of Ethiopia: Education Statistics Annual Abstract, 2004 E.C (2011/2012). Edited by EMIS PaRMD. Addis Ababa, Ethiopia: Federal Ministry of Education of Ethiopia; 2012.

26. Baer JS, Kivlahan DR, Blume AW, McKnight P, Marlatt GA: Brief intervention for heavy-drinking college students: 4-year follow-up and natural history. Am J Public Health 2001, 91(8):1310-1316.

27. Tessema KA: The unfolding trends and consequences of expanding higher education in Ethiopia: massive universities, massive challenges. High Educ Q 2009, 63(1):29-45.

28. Ageely HM: Prevalence of Khat chewing in college and secondary (high) school students of Jazan region, Saudi Arabia. Harm Reduct J 2009, 6(11):3.

29. Brady KT, Randall $\mathrm{CL}$ : Gender differences in substance use disorders. Psychiatr Clin N Am 1999, 22(2):241-252.

30. Kulis S, Marsiglia FF, Ayers SL, Booth J, Nuño-Gutiérrez BL: Drug resistance and substance use among male and female adolescents in alternative secondary schools in Guanajuato, Mexico. I Stud Alcohol Drugs 2012, 73(1):111-119.

31. Stevenson M, Fitzgerald J, Banwell C: Chewing as a social act: cultural displacement and Khat consumption in the East African Communities of Melbourne. Drug Alcohol Rev 1996, 15:73-82.

32. Room R: Multicultural contexts and alcohol and drug use as symbolic behaviour. Addict Res Theory 2005, 13(4):321-331.

33. Andrews JA, Tildesley E, Hops H, Li F: The influence of peers on young adult substance use. Health Psychol 2002, 21(4):349.

34. Allen JP, Chango J, Szwedo D, Schad M, Marston E: Predictors of susceptibility to peer influence regarding substance use in adolescence. Child Dev 2012, 83(1):337-350.

35. Mahfouz MS, Alsanosy RM, Gaffar AM: The role of family background on adolescent khat chewing behavior in Jazan Region. Ann Gen Psychiatry 2013, 12(1):16

36. Park A, Sher K, Krull JL: Selection and socialization of risky drinking during the college transition: the importance of micro-environments associated with specific living units. Psychol Addict Behav 2009, 23(3):404-414.

37. Carmody TP, Delucchi K, Simon JA, Duncan CL, Solkowitz SN, Huggins J, Lee SK, Hall SM: Expectancies regarding the interaction between smoking and substance use in alcohol-dependent smokers in early recovery; 2011.

38. Teter CJ, McCabe SE, Cranford JA, Boyd CJ, Guthrie SK: Prevalence and motives for illicit use of prescription stimulants in an undergraduate student sample. J Am Coll Heal 2005, 53(6):253-262.

39. Arria AM, DuPont RL: Nonmedical prescription stimulant use among college students: why we need to do something and what we need to do. J Addict Dis 2010, 29(4):417-426.

40. Ayana A, Mekonen Z: Khat (Catha edulis Forsk) chewing, sociodemographic description and its effect on academic performance, Jimma University students 2002. Ethiop Med J 2004, 42(2):125-136.

41. Al-Sanosy RM: Pattern of khat abuse and academic performance among secondary school and college students in jazan region, kingdom of saudi arabia (ksa). J Fam Community Med 2009, 16(3):89-95.

42. Dean AC, Hellemann G, Sugar CA, London ED: Educational attainment is not a good proxy for cognitive function in methamphetamine dependence. Drug Alcohol Depend 2012, 123(1):249-254.

43. Brenneisen R, Fisch HU, Koelbing U, Geisshusler S, Kalix P: Amphetamine-like effects in humans of the khat alkaloid cathinone. Br J Clin Pharmacol 1990, 30(6):825-828.

44. Patel NB: Mechanism of action of cathinone: the active ingredient of khat (Catha edulis). East Afr Med J 2000, 77(6):329-332

45. Hall DA, Stanis JJ, Avila HM, Gulley JM: A comparison of amphetamine-and methamphetamine-induced locomotor activity in rats: evidence for qualitative differences in behavior. Psychopharmacology 2008, 195(4):469-478.

\section{Submit your next manuscript to BioMed Central and take full advantage of:}

- Convenient online submission

- Thorough peer review

- No space constraints or color figure charges

- Immediate publication on acceptance

- Inclusion in PubMed, CAS, Scopus and Google Scholar

- Research which is freely available for redistribution 